\title{
Development and Assessment of Postcranial Sex Estimation Methods for a Guatemalan Population*
}

\author{
Gillian Fowler, ${ }^{1}$ M.Sc.; and Cris Hughes, ${ }^{2}$ Ph.D.
}

${ }^{1}$ School of Life Sciences, University of Lincoln, Joseph Banks Laboratories, Green Lane, Lincoln, LN6 7DL, United Kingdom.

2Department of Anthropology, University of Illinois at Urbana-Champaign, 109

Davenport Hall, 607 S. Matthews Avenue, Urbana, IL 61801.

${ }^{*}$ Presented at the $66^{\text {th }}$ Annual Scientific Meeting of the American Academy of Forensic Sciences, February 17-22, 2014, in Seattle, WA. 
ABSTRACT: This study tests whether postcranial sex estimation methods generated from Hispanic, and mainly Mexican samples, can be successfully applied to other increasingly common migrant populations from Central America. We use a sample of postcranial data from a modern (1980s) Guatemalan Maya sample ( $\mathrm{n}=219)$. Results indicate a decrease in classification accuracies for previously established univariate methods when applied to the Guatemalan study sample, specifically for males whose accuracies ranged from $30-84 \%$. This bias towards inaccuracies for Guatemalan males is associated with the smaller skeletal sizes for the Guatemalan sample as compared to the samples used in the tested sex estimation methods. In contrast, the tested multivariate discriminant function classification yielded less sex bias and improved classification accuracies ranging from 82-89\%. Our results highlight which of the tested univariate and multivariate methods reach acceptable levels for accuracy for sex estimation of cases where the region of origin may include Guatemala.

KEYWORDS: forensic science, forensic anthropology, Hispanic, sex estimation, postcranial measurements, migrant 
While Mexico remains a primary sending country for undocumented border crossers (UBC) at the U.S-Mexico border (1), recent years demonstrate an influx in migrants from Central and South American countries (2) as well as an increase in unaccompanied minors from the Northern Triangle countries of Guatemala, El Salvador and Honduras (3-6). In the last decade (20002013) in the U.S., the Central American population has increased by 56\%, with Guatemalans being one of the lead sending countries from this region (7). These statistics are concomitantly reflected in the trends of those who die while attempting to cross. According to Martinez and colleagues' (8), analysis of over twenty years of death investigation cases of deceased UBCs from the Pima County Medical Examiner's Office (PCOME) in Tucson, Arizona, nearly 83\% of those identified cases are Mexican nationals, with the next most prevalent country of origin being Guatemala (7\%). There are a number of reasons as to why the rate of Central and South American UBCs is increasing, including the incumbent social, political and economic conditions in the sending countries $(3,5,6)$.

In the context of the medico-legal death investigations of UBC cases, the cultural and biological diversity of the migrating demographic can make the identification process difficult in unique ways, yet is not necessarily explicitly reflected in forensic anthropology methods. For example, a basic concern is how the changing population diversity of migrants comprising the UBC demographic impacts the accuracy of the methods being applied to estimate the biological profile, such as sex, age and stature estimations.

The present study examines how reference sampling impacts the accuracy of methods which can be used in UBC casework, and whether they can be applied to the changing UBC demographic of Central Americans. Because UBC sending regions have markedly expanded in 
recent decades, we propose that a concurrent expansion of skeletal diversity of the UBC demographic has also occurred. Specifically, the present study explores whether diversity in body size is captured in established postcranial sex estimation methods applicable to the current UBC demographic $(9,10)$.

Previous studies (9-11) were led by researchers who identified a similar issue of a changing forensic anthropology UBC casework demographic, recognizing that the available methods at that time were drawn from a Latino demographic that did not adequately encompass the skeletal diversity of those who were crossing the border (B.E. Anderson pers. comm.). Specifically, Tise (11) and colleagues (9) addressed the shift from larger-bodied migrants from northern Mexican states to the expanded sending regions across Mexico, reflecting an increased variation in body size in their postcranial sectioning points for sex estimation. More recently, Spradley and colleagues (10) expanded on previous sampling efforts and produced subsequent sex estimation methods based on the inclusion of a southern Mexico sample. The expansion of sampling to a location where Mayan indigenous ancestry is prevalent effectively increased the representation of smaller-bodied individuals in the sample and methods. These sampling and method adjustments are reflective of the trends witnessed in the UBC demographic over the past 15 years, which indicate a marked increase in the number southern and central Mexico origins of Mexican migrants $(8,12,13)$. The present study builds on these previous works by considering the most recent shifts in the UBC demographic, the Guatemalan migrant.

Migrants from Guatemala have consistently increased in recent years, (7), with a particular influx from poverty-stricken areas $(6,14)$, which generally overlaps with those departments with the largest rural and indigenous Maya populations. Average body size of indigenous Guatemalans living in Guatemala has been demonstrated to differ significantly when 
compared to indigenous Guatemalans who experience less social, economic and environmental stress, such as descendants of Maya refugees in the U.S. (15). Thus, Guatemalan migrants who are crossing into the U.S. potentially represent a UBC demographic whose smaller body size may not necessarily be reflected in the current reference samples and postcranial sex estimation methods.

The aims of the present study are 1) to assess whether established accuracies for UBC postcranial sex estimation methods are upheld when applied to an indigenous Guatemalan sample, and 2) based on the results of the study’s first aim, make recommendations regarding which methods (e.g. univariate or multivariate methods; particular measurements) are most appropriate for the expanding UBC demographic.

\section{Common Reference Sampling Strategies for Methods Development}

Because most border-crossing cases that require a forensic anthropologist are not identified at the time of analysis, the reference samples from which the anthropological methods derive require thoughtful consideration. Because the origin of the unidentified decedent is unknown, the individual may be from a sending region whose skeletal variation is poorly reflected in a given method's sample diversity. One approach to generating an appropriate sample from which to establish forensic anthropology methods has been to source actual UBC cases, which may or may not have been identified. While an intuitive first step, secular changes in the border crossing demographic, as previously highlighted, require that this sample be consistently updated. Using identified UBC cases intuitively is preferred, as researchers can confirm that the decedent is included in the demographic of interest for method sampling. However, Hughes and colleagues (16) have demonstrated an identification bias in border-crosser 
casework from recent years, where those individuals who have been identified exhibit a greater amount of European ancestry, as compared to those UBCs not yet identified. Therefore, if methods are derived from a sample of identified border crosser cases only, then the demographic may not necessarily represent who is dying, but only who is dying and being identified. In this situation, sampling only identified UBC cases may yield a sample that is skewed towards greater European admixture than what is represented among all deceased UBCs, regardless of identification status.

There are several contextual factors in UBC casework that render sex estimation more challenging than other forensic anthropological casework demographics. Often, a comprehensive application of the array of available sex estimation methods for human skeletal remains is not always possible with UBC cases, as many cases constitute only a partially recovered skeleton (B.E. Anderson pers. comm.). Furthermore, those skeletal elements present in a given UBC case commonly exhibit extensive taphonomic processes (e.g. cortical erosion, carnivore gnawing) which further limit the application sex estimation methods. Because of the sometimes limited availability of skeletal material, methods that use a single measurement from a single skeletal element, such as univariate sectioning points, are ideal for UBC casework, and thus the present study follows the approach of previous studies (9-11) in developing univariate sectioning points for sex estimation.

Another challenge common in the UBC casework context is DNA availability. In other forensic contexts, the anthropological sex estimation may be confirmed with DNA analysis, thus resolving any inaccurate information generated. In contrast, a misclassification of sex from forensic anthropological methods may not be resolved from DNA in the UBC context, as the DNA may be more degraded (due to an extended post-mortem interval under hot and dry 
conditions) to the point where genetically-derived information on sex is not available for comparison (pers. comm. with B.E. Anderson).

As the ultimate goal is to identify the decedents and return them to their families, it is imperative that forensic anthropologists develop and employ sex estimation methods that are well balanced in both accuracy and precision for the most current border crossing demographic.

\section{Materials and Methods}

\section{Study Sample}

The sample data in the present study was collected from Forensic Anthropology Foundation of Guatemala (FAFG) cases of victims from the Guatemalan civil war (1960-1996), including 51 females and 168 males. The individuals included in the sample are geographically diverse, including 59 different grave sites located across the Guatemala highlands, from over five departments; Quiche, Chimaltenango, Baja Verapaz, Alta Verapaz and Solola. Based on the documentation of the gravesites, the majority of the sampled individuals date to the early 1980s, at the height of the civil war's violence according to the United Nations-sponsored Historical Clarification Commission (CEH) report (17). Data collection was completed by author CEH intermittently from 2006-2009. The estimated sex of each individual was drawn from the FAFG forensic anthropology reports, which used a variety of methods (depending on element availability) to assess sex, including traditional nonmetric methods (pelvic and cranial gross morphology) and metric methods (18-20). In the sample $49 \%$ of males and $69 \%$ of females were identified. In the cases where the individual was not identified, only instances where the final sex estimation was calculated using several methods and inference of sex was strong were utilised in 
this study. Estimations of sex that were probable or possible male or female were excluded from the sample. Additionally clothing in the Guatemalan Mayan community is traditionally sexspecific and is used as corroboration by the caseworker to confirm the anthropological sex estimation. The majority (83\%) of the reported missing persons related to the civil war were indigenous (17), and thus the study sample used here reflects a largely indigenous sample. This demographic mainly represents the population from Guatemala that is making the journey north, who are from poorer rural areas in search of economic opportunities (14).

\section{Data Collection}

Twenty-three standard postcranial measurements $(21,22)$ were collected by author CEH. Digital sliding calipers and an osteometric board were used to collect the measurements. When taphonomic processes (e.g. damage, erosion, partial recovery) and/or trauma were present, the collections of the affected measurements on all individuals were not completed. Therefore, measurement-specific samples sizes are included in appropriate tables throughout the paper. Of the 23 measurements collected, only those measurements with a sample size greater than or equal to 20 for each sex are reported here, yielding nine postcranial measurements for the following analyses (see Table 1 for the measurement descriptions).

\section{Data Analysis: Guatemalan Sex Differences and Sectioning Points}

For those nine postcranial measurements with samples sizes greater than or equal to 20, basic test statistics were generated for male and females, with subsequent ANOVA tests. ANOVA tests that yielded significant differences (with a Bonferroni-corrected $\alpha=0.006$ ) were then used to develop sex estimation methods for the Guatemalan sample. Basic statistics and 
sectioning points were generated for comparison with other studies' (9-11) established sectioning points, which have been applied in forensic anthropological casework.

Sectioning points were generated for each postcranial measurement by summing the male and female means and dividing by two. Because a sectioning point is typically represented as an integer, the researcher must define what the appropriate interval attached to this integer will be. When postcranial measurements are collected using digital calipers, a non-integer value (e.g. with decimals) is produced, and thus the researcher typically rounds these decimals to the nearest integer. Therefore, we define the interval representing a sectioning point as half the distance to the nearest integers above and below the sectioning point. For example, if the sectioning point for humeral head vertical diameter is established as $40 \mathrm{~mm}$, then the numeric interval considered as the sectioning point would be 39.5 to $40.5 \mathrm{~mm}$. Any sampled individual whose humeral head vertical diameter measures within this range would be considered indeterminate sex. To calculate classification rates of the sectioning points, the number of individuals who were indeterminate was subtracted from the original sample size to yield an adjusted sample of only classified (correctly or incorrectly) individuals. Classification rates for the Guatemalan sample were generated for males and females using the sectioning points generated presently.

Data Analysis: Test of Classification Accuracy for Guatemalan Samples in Previously Established Sex Estimation Methods

The 23 postcranial measurements for which adequate data are present in the Guatemalan sample were narrowed down to those measurements which have been previously used in studies that established sectioning points for sex estimation of Hispanics (9-11), as these studies are based on two relevant samples: border-crosser cases at the Pima County Office of the Medical 
Examiner $(9,11)$ and a combined sample of historic Mexicans (from Hidalgo and Yucatan) and PCOME cases identified as Mexican (10). Of the available Tise (11) sectioning points (referred to henceforth as TSP), thirteen matched those with data available for the male and female Guatemalan sample. Of the available Spradley et al. (10) sectioning points (referred to henceforth SSP), five matched those with data available for the male and female Guatemalan sample. Because the Guatemalan sample is being used as a test sample for gauging the classification accuracy of these two sectioning point methods for this newer border crossing demographic, there is no minimum or consistent sample size per postcranial measurement. Instead, all available data are used to test methods accuracy and sample sizes are reported per sex per sectioning point in tables below.

Furthermore, a test sample of nine females and thirty-four males from the Guatemalan sample was used to test the femur discriminant classification function for Mexican Hispanics reported in Spradley et al. (10). The sample size was constrained by the measurements available in the Guatemalan sample that could be tested.

\section{Results}

Guatemalan Sample: Sex Variation and Sectioning Points

Table 1 provides ANOVA results for comparing Guatemalan male and female postcranial measurements. Prior to performing the ANOVA analyses, tests for equal variances for males and females were performed for each postcranial measurement. None of these tests yielded significant differences in variance. ANOVA tests yielded significant differences (with a Bonferroni-corrected $\alpha=0.006$ ) for all nine comparisons of male and female means, and were thus suitable variables for developing sex estimation methods. The adjusted $R^{2}$ values range from 
0.26-0.50, indicating that sex differences account for a significant portion of the variation present in these measurements. Table 2 provides the Guatemalan male and female sectioning points, the adjusted sample sizes (only those classified as male or female, and thus excluding “indeterminate" cases as described in Methods), and their associated classification rates. For males, the lowest classification rate is $79.03 \%$ (anterior-posterior diameter at midshaft of the femur) and the greatest classification rate is $94.66 \%$ (maximum diameter of femoral head). For females the lowest classification rate is $77.27 \%$ (transverse diameter of the femur at midshaft) and the greatest classification rate is $96.00 \%$ (maximum diameter of humeral head). As a forensic anthropological sexing method, these sectioning points are useful in a limited context, such as the analysis of victims of the Guatemalan civil war. The main purpose for generating the sectioning points in the present study is for comparison with classification rates of existing sectioning points applicable to border crosser casework (9-11).

[Insert Tables 1 and 2 here]

\section{Testing Classification Accuracies of SSP and TSP Methods}

The Guatemalan study sample was treated as a test sample for classification accuracy of the TSP and SSP methods. Table 3 provides a comparison of the classifications rates for the two methods. SSP consistently classifies the Guatemalan test sample more accurately than the TSP for males, with accuracy ranging from $66.95-84.17 \%$ compared to the TSP sample, which ranges from 30.51-68.69\%. The female sample is more consistent between the SSP and TSP samples with accuracies over $80 \%$ for both. These accuracies are consistent with what is known about the two samples used to generate these sectioning points, as the SSP reference sampling included some individuals within the Maya region of Mexico which likely exhibited smaller 
measurements for both males and females, and thus more representative of the smaller Guatemalan measurements included in the sample here.

[Insert Table 3 here]

In general, when compared with the classification rates using the Guatemalan sectioning points (Table 2), the two alternative methods have sectioning points that are skewed toward larger body size (e.g. greater sectioning point values). This is indicated by the trends in classification rates between the male and female Guatemalans (Table 3), with females consistently exhibiting higher accuracies for all TSP and SSP sectioning points. Specifically, the male test sample experiences a 30-50\% drop in classification accuracy when comparing the results of the five shared sectioning points between the Guatemalan (Table 2) and the TSP (Table 3) samples (including maximum diameter of the humeral head, maximum diameter of the femoral head, maximum length of the femur, maximum length of the tibia, and the transverse diameter of the femur at midshaft), whereas the SSP method exhibits a 10-26\% drop in male classification accuracy when compared with two of the shared sectioning points with the Guatemalan sample (maximum diameter of the humeral head, maximum diameter of the femoral head). The SSP method therefore exhibits a considerable improvement over the TSP classification rates. Of the SSP's five sectioning points for which Guatemalan postcranial measurements were available, three of these generated high accuracy rates (greater than or equal to $80 \%$ ) for Guatemalan males, while none of the TSP method's thirteen sectioning points included here reach this threshold for Guatemalan males (Table 3).

The Guatemalan male classification rate discrepancies between the TSP and SSP methods are likely a result of the larger body bias in the TSP sample. Table 4 highlights this trend by comparing the means for males across all comparable postcranial measurements for all 
three study samples: the present study's Guatemalan sample, TSP, and SSP. The Guatemalan study sample consistently exhibits the smallest means, the TSP sample exhibits the greatest means, and the SSP sample exhibits intermediate means. Interestingly, several of the standard deviations are comparable (maximum radius, humerus and clavicle measurements) for the Guatemalan, SSP and TSP studies’ samples, suggesting that the Guatemalan sample is as diverse as those studies drawing from a variety of source populations. This heterogeneity ultimately impacts the accuracy of the sectioning points as a method, and emphasizes the need for methods that capture the actual diversity of the border crosser demographic.

When tested with the Guatemalan sample, the discriminant function analysis (DFA) classifications using Spradley and colleagues’ function (10) for the femur misclassified six out of the 34 males and one out of the nine females, with classification percentages of $82.35 \%$ and 88.89\% respectively. The cross-validated classification rate for the femur reported in Spradley et al. (10) is $85.94 \%$ for males and $100 \%$ for females, which is slightly greater for males and significantly greater for females than the results for the Guatemalan sample. Regardless of the classification differences, the present study's classification percentages using the SSP DFA of femoral measurements indicates that the DFA has an acceptable classification percentage of over $80 \%$ for the Guatemalan males and females.

\section{Discussion}

The results of the present study indicate that current sex estimation methods potentially applied to UBC casework are biased towards a specific UBC demographic that does not fully encompass the most current migrant demographic trends. Explicitly, current methods misclassify Guatemalan males who are on the lower end of the spectrum for Hispanic male body size. 
However, the bias is minimal for several of the postcranial measurements for the SSP method, including ulnar maximum length, biepicondylar breadth of the humerus, and maximum vertical diameter of the femoral head. These three sectioning points provide accurate classification rates of $80 \%$ or more for the Guatemalan samples, suggesting that these three sectioning points can be applied to UBC casework for a wide range of migrants, including indigenous Guatemalans.

Beyond explicit classification rates, patterns of classification accuracy for the Guatemalan sample were considered, based on the results in Table 3. When assessing classification accuracy of the TSP method, postcranial measurements on or near epiphyses tended to outperform maximum long bone length measurements of the lower extremity. Furthermore in both SSP and TSP methods, maximum lengths for bones of the lower extremity are less accurate for the Guatemalan sample than similar metrics for the upper extremity. We see general consistency in accuracies for specific measurements for the two methods, with the topperforming sectioning points being the same for both the TSP and SSP methods: ulnar maximum length, biepicondylar breadth of the humerus, and maximum vertical diameter of the femoral head. The results support that the SSP method for these three postcranial measurements are the most appropriate for estimating sex for UBC cases of unknown origin.

It is often purported that a multivariate approach (e.g. DFA) is preferable to a univariate approach, as more independent variables can potentially better approximate the dependent variable of interest. The present study’s test of Spradley and colleagues' (10) femoral DFA found that the rate of misclassifications were similar to their best-performing univariate sectioning points for the Guatemalan test sample. In UBC casework, more often than not only incomplete skeletons are recovered, and often exhibit damage from taphonomic processes such as scavenging or erosion. Because the DFA requires all measurements in the function to be present, 
this limitation reduces the likelihood that the method can be used on a range of cases. When all measurements are available, this method is appropriate to use, as the classification accuracies of were acceptable for Guatemalan males and females (82\%-89\%).

\section{Sampling Strategies and Potential Identification Biases}

The complex context of the border and the shifting trends in who is migrating require us to think more critically about approaches to sampling for methods development for UBC casework, and how this impacts not only method accuracy but ultimately the identification process itself. The results of the present study highlight this point in important ways. The study sample used here is comprised of the very families that suffered the most during the protracted violence in Guatemala, whose communities have continued to live in a time of poverty and violent crime, a legacy of the civil war. Consequently, these are the same individuals who are more susceptible to migration and yet have a greater risk of death while migrating, as they must travel across two borders (Reineke and Martinez 2014). The lasting, yet justified distrust of the state (whether their own or the U.S) makes it difficult to collect information about who is actually migrating and who has gone missing during their migration. Collecting DNA samples to identify the missing is also difficult in this context, even when the agency is not affiliated with the state, as some families are concerned about the security of their data and how it used; for example, there is concern it may be used to identify and deport their undocumented family members in the U.S. (Marco Perez, personal communication). Furthermore, many of the rural impoverished Guatemalans who migrate to the U.S. speak indigenous languages, making it challenging to access resources available to Spanish-speaking migrants, such as help hotlines, NGOs, or authorities. These vulnerabilities are, to an extent, experienced by all migrants, and 
have a direct impact on the ability to successfully identify those who die in transit (16).

However, certain migrants undergo heightened vulnerabilities that stratify the migrant demographic in gradations of marginalization.

Forensic anthropologists must ensure that our methods for generating a biological profile do not reify these marginalizations. For example, when sex estimation methods are developed that represent the traditional majority of migrants (e.g. Mexicans), yet fail to represent other common migrants (such as rural indigenous Guatemalans), the increased misclassifications of sex for this particular migrant demographic disproportionately reduces the chance of identification in a population that already has the most hurdles impeding their odds of being successfully identified. The present study highlights the existing complexities of developing applicable methods to UBC casework, while simultaneously managing outcomes which could potentially prioritize the (mis)identification of one UBC demographic (i.e. larger bodied) over another. Several methodological approaches can assist in mitigating this issue. In particular, a comprehensive sample should be used to develop sex estimation methods, as the ancestry and national origin are not likely known for an unidentified border crosser. By combining samples that represent border crosser sending regions, accuracy will be balanced across the samples, instead of being biased towards a particular demographic. For example, the SSP method is based on a geographically and ancestrally diverse sample, and is thus more accurate for classification of Guatemalans than the TSP method. However, it is important to also note the lack of success for the SSP method, as two of the five sectioning points analysed here exhibit only moderate classification success (see Table 3: vertical diameter of humeral head: $66.95 \%$ for males; maximum length of clavicle: 70.83\% for males). These under-performing sectioning points suggest that more comprehensive validation is required for sectioning points applicable to a diverse border crosser demographic. 
The authors propose that as diverse a sample as possible be assembled from the various studies (present study included) to generate a more representative sample from which to generate methods.

\section{Broader Implications for UBC Biological Profile Assessment}

There are broader implications to be considered concerning the assessment of the biological profile for UBC cases. This study has demonstrated the inconsistent accuracies of current postcranial sexing methods when applied to the changing UBC demographic. It is intuitive that other components of the biological profile will also be impacted by the increasing diversity of who is crossing the U.S.-Mexico border. For example, stature estimates will also be impacted, as highlighted here with the smaller maximum long bone lengths for the indigenous Guatemalan sample. As traditional biological profile methods’ applicability is assessed, and new methods are developed that are representative of UBC diversity, the potential for identification and repatriation of decedents from the U.S.-Mexico border will continue to improve.

Another worrying trend is the increase in migration of family units (defined as a group which includes a minor) and unaccompanied minors from the Central American Northern Triangle countries, which includes Guatemala, along with El Salvador and Honduras. These three countries are especially vulnerable to migration as many are escaping gang-related violence and poverty which are cited as the two main causes (5). The number of border apprehensions from these groups is increasing, compared to the number from Mexico (6), and as a general trend, reflects the changing demographic at the border. With the number of migrants from Honduras and El Salvador on the rise, additional studies will need to be performed to revisit the recommendations for specific methods endorsed in the present study; continual critical 
assessment of our current methods for an ever-changing case demographic is a well-established best practice in forensic anthropology (16,23-25).

\section{Acknowledgements}

The authors would like to thank the Forensic Anthropology Foundation of Guatemala (FAFG) for allowing the data collected to be used for publication. The authors also wish to thank Dr. Bruce Anderson for his communications and comments on the manuscript. We also thank Marco Perez for his useful insights into Guatemalan indigenous perspectives and interactions with the identification process. 


\section{References}

1. Passel JS, Cohn D. Unauthorized immigrant totals rise in 7 states, fall in 14 . Washington, DC: Pew Research Center, 2014 Nov 18; http://www.pewhispanic.org/2014/11/18/chapter-2-birthplaces-of-u-s-unauthorizedimmigrants/ (accessed October 1, 2015).

2. Krogstad JM, Passel JS. U.S. border apprehensions of Mexicans fall to historic lows. Washington, DC: Pew Research Center, 2014 Dec 30; http://www.pewresearch.org/facttank/2014/12/30/u-s-border-apprehensions-of-mexicans-fall-to-historic-lows/ (accessed October 1, 2015).

3. Washington Office on Latin America. Advocacy for human rights in the Americas five facts about migration from Central America's northern triangle: migration is driven by violence and insecurity; deportations are inhumane and put returnees at risk, 2016; http://www.wola.org/commentary/five_facts_about_migration_from_central_america_s_ northern_triangle (accessed February 15, 2017).

4. U.S. Customs and Border Protection. Southwest border inadmissibles by field office: Southwest border unaccompanied alien children (0-17 yr old) inadmissibles, 2017; https://www.cbp.gov/newsroom/stats/ofo-sw-border-inadmissibles (accessed February 15, 2017).

5. United States Government Accountability Office. Central America information on migration of unaccompanied children from El Salvador, Guatemala, and Honduras, 2015; http://www.gao.gov/assets/670/668749.pdf (accessed October 1, 2015). 
6. United States Conference of Catholic Bishops. Mission to Central America: the flight of unaccompanied children to the United States: report of the Committee on Migration of the United States, 2013; http://www.usccb.org/about/migration-policy/upload/MissionTo-Central-America-FINAL-2.pdf (accessed October 1, 2015).

7. Migration Policy Institute. Central American immigrants in the United States, 2015; http://www.migrationpolicy.org/article/central-american-immigrants-united-states. (accessed October 1, 2015).

8. Martinez DE, Reineke R, Rubio-Goldsmith R, Anderson BE, Hess GL, Parks BO. A continued humanitarian crisis at the border: undocumented border crosser deaths recorded by the Pima County Office of the Medical Examiner, 1990-2012 (June 1, 2013); http://dx.doi.org/10.2139/ssrn.2633209 (accessed October 1, 2015).

9. Tise ML, Spradley MK, Anderson BE. Postcranial sex estimation of individuals considered Hispanic. J Forensic Sci 2013;58(Suppl 1):S9-14

10. Spradley MK, Anderson BE, Tise ML. Postcranial sex estimation criteria for Mexican Hispanics. J Forensic Sci 2015;60(Suppl 1):27-31.

11. Tise M. A metric analysis of the postcranial skeleton of Hispanic individuals to improve estimation of sex [thesis]. San Marcos, TX: Texas State University, 2010.

12. Reineke R, Martinez DE. Migrant deaths in the Americas. In: Brian T, Laczko F, editors. Fatal journeys tracking lives lost during migration. Geneva, Switzerland: International Organization for Migration, 2014;45-75.

13. Rubio-Goldsmith R, McCormick MM, Martinez D, Duarte IM. The "funnel effect” and recovered bodies of unauthorized migrants processed by the Pima county office of the medical examiner, 1990-2005. Tucson, AZ: Binational Migration Insititute, 2006. 
14. Cheikhrouhou H, Jarque R, Hernández-Coss R, El-Swaify R. The U.S.-Guatemala remittance corridor: understanding better the drivers of remittances intermediation. World Bank Working Paper No. 86. Washington, DC: World Bank. (C) World Bank, 2006; https://openknowledge.worldbank.org/handle/10986/7172 License: CC BY 3.0 IGO (accessed October 1, 2015).

15. Bogin B, Smith P, Orden AB, Varela Silva MI, Loucky J. Rapid change in height and body proportions of Maya American children. Am J Hum Biol 2002;14(6):753-61.

16. Hughes CE, Algee-Hewitt BFB, Clausing E, Anderson B. Temporal patterns of Mexican migrant ancestry: implications for Identification. Proceedings of the 67th Annual Scientific Meeting of the American Academy of Forensic Sciences; 2015 Feb 16-21; Orlando, FL. Colorado Springs, CO: American Academy of Forensic Sciences, 2015;47.

17. Commission for Historical Clarification (CEH). Guatemala memory of silence: report of the Commission of Historical Clarification Conclusions and Recommendations, 1999; https://www.documentcloud.org/documents/357870-guatemala-memory-of-silence-thecommission-for.html. (accessed October 1, 2015).

18. Frutos LR. Determination of sex from the clavicle and scapula in a Guatemalan contemporary rural indigenous population. Am J Forensic Med Pathol 2002;23(3):284-8.

19. Frutos LR. Brief communication: Sex determination accuracy of the minimum superoinferior femoral neck diameter in a contemporary rural Guatemalan population. Am J Phys Anthropol 2003;122:123-126.

20. Frutos LR. Metric determination of sex from the humerus in a Guatemalan forensic sample. Forensic Sci Int 2005;147(2):153-7. 
21. Buikstra JE, Ubelaker DH, editors. Standards for data collection from human skeletal remains. Series No. 44. Fayetteville, AR: Arkansas Archaeological Survey Research, 1994.

22. Moore-Jansen PH, Ousley SD, Jantz RL. Data collection procedures for forensic skeletal material. Report No.: 48. Knoxville, TN: Department of Anthropology, The University of Tennessee, 1994.

23. Algee-Hewitt BFB. Population inference from contemporary American craniometrics. Am J Phys Anthropol 2016;160:604-24.

24. Spradley MK, Jantz RL, Robinson A, Peccerelli F. Demographic change and forensic identification: problems in metric identification of Hispanic skeletons. J Forensic Sci 2008;53(1):21-8.

25. Jantz LM, Jantz RL. Secular change in long bone length and proportion in the United States, 1800-1970. Am J Phys Anthropol 1999;110(1):57-67. 
TABLE 1—Basic statistics and ANOVA test results for Guatemala study sample, unit in millimetres.

\begin{tabular}{|c|cccc|ccc|}
\hline & \multicolumn{7}{|c|}{ Adjusted } \\
Measurement & Sex & $n$ & Mean & SD & $\mathrm{R}^{2}$ & F-ratio & $p$ \\
\hline Glenoid Cavity Breadth & $\mathrm{F}$ & 32 & 22.69 & 2.17 & 0.36 & 97.58 & $<0.0001$ \\
& $\mathrm{M}$ & 144 & 26.24 & 1.75 & & & \\
\hline Glenoid Cavity Height & $\mathrm{F}$ & 36 & 31.47 & 1.70 & 0.47 & 165.28 & $<0.0001$ \\
& $\mathrm{M}$ & 150 & 35.81 & 1.85 & & & \\
\hline Humerus Max Diam & $\mathrm{F}$ & 27 & 37.19 & 1.69 & 0.46 & 141.61 & $<0.0001$ \\
& $\mathrm{M}$ & 140 & 42.83 & 2.35 & & & \\
\hline Fem. Max. Vert. Head & & & & & & & \\
Diam. & $\mathrm{F}$ & 32 & 38.13 & 2.07 & 0.50 & 175.28 & $<0.0001$ \\
& $\mathrm{M}$ & 143 & 43.82 & 2.23 & & & \\
\hline Fem. Trans. Diam. Midshaft & $\mathrm{F}$ & 28 & 21.93 & 1.75 & 0.39 & 63.51 & $<0.0001$ \\
& $\mathrm{M}$ & 71 & 24.88 & 1.63 & & & \\
\hline Fem. AP Diam. Midshaft & $\mathrm{F}$ & 29 & 23.63 & 2.25 & 0.26 & 36.37 & $<0.0001$ \\
& $\mathrm{M}$ & 71 & 26.49 & 2.12 & & & \\
\hline Femur Max. Length & $\mathrm{F}$ & 22 & 384.05 & 17.34 & 0.41 & 57.37 & $<0.0001$ \\
& $\mathrm{M}$ & 60 & 419.45 & 19.23 & & & \\
\hline Fem. Bicondylar Length & $\mathrm{F}$ & 21 & 382.19 & 17.01 & 0.41 & 54.86 & $<0.0001$ \\
& $\mathrm{M}$ & 58 & 417.22 & 19.09 & & & \\
\hline Tibia Length & $\mathrm{F}$ & 22 & 315.82 & 19.24 & 0.38 & 46.94 & $<0.0001$ \\
& $\mathrm{M}$ & 55 & 348.76 & 18.99 & & & \\
\hline
\end{tabular}


TABLE 2-Guatemalan study sample sectioning points, sex-specific adjusted sample sizes, and their associated classification rates.

\begin{tabular}{|c|c|c|c|c|c|c|}
\hline Measurement & $\begin{array}{l}\text { Sectioning } \\
\text { Point mm }\end{array}$ & $\begin{array}{c}\text { Adjusted } \\
\text { Sample } \\
\text { Size Female }\end{array}$ & $\begin{array}{c}\text { Adjusted } \\
\text { Sample Size } \\
\text { Male }\end{array}$ & $\begin{array}{c}\text { Correct } \\
\text { Classification } \\
\text { Female } \\
\end{array}$ & $\begin{array}{c}\text { Correct } \\
\text { Classification } \\
\text { Male } \\
\end{array}$ & $\begin{array}{c}\text { Overall } \\
\text { Classification } \\
\text { Rate }\end{array}$ \\
\hline Hum. Head Max. Diameter & 40 & 25 & 130 & $96.00 \%$ & $93.08 \%$ & $94.54 \%$ \\
\hline Fem. Head Max. Vert. Diam. & 41 & 32 & 131 & $90.63 \%$ & $94.66 \%$ & $92.65 \%$ \\
\hline Glenoid Cavity Breadth & 24 & 26 & 135 & $88.46 \%$ & $94.07 \%$ & $91.27 \%$ \\
\hline Glenoid Cavity Height & 34 & 34 & 134 & $94.12 \%$ & $87.31 \%$ & $90.72 \%$ \\
\hline Fem. Bicondylar Length & 400 & 21 & 58 & $95.24 \%$ & $82.76 \%$ & $89.00 \%$ \\
\hline Femur Max. Length & 402 & 21 & 60 & $95.24 \%$ & $81.67 \%$ & $88.46 \%$ \\
\hline Tibia Length & 332 & 21 & 54 & $85.71 \%$ & $83.33 \%$ & $84.52 \%$ \\
\hline Fem. Trans. Diam Midshaft & 23 & 22 & 61 & $77.27 \%$ & $90.16 \%$ & $83.72 \%$ \\
\hline Fem. AP Diam. Midshaft & 25 & 25 & 62 & $80.00 \%$ & $79.03 \%$ & $79.52 \%$ \\
\hline
\end{tabular}


TABLE 3-Classification of male and female Guatemalan samples using two sectioning point methods.

\begin{tabular}{|c|c|c|c|c|c|c|c|}
\hline \multirow[b]{2}{*}{ Measurement } & \multirow[b]{2}{*}{$\begin{array}{c}\text { Sample } \\
\text { size (male, } \\
\text { female) }\end{array}$} & \multicolumn{3}{|c|}{ TSP Method \% Accuracies } & \multicolumn{3}{|c|}{ SSP Method \% Accuracies } \\
\hline & & $\begin{array}{l}\text { Sectioning } \\
\text { Point mm }\end{array}$ & Male & Female & $\begin{array}{l}\text { Sectioning } \\
\text { Point mm }\end{array}$ & Male & Female \\
\hline $\begin{array}{l}\text { Ulna Maximum } \\
\text { Length }\end{array}$ & 33,6 & 248 & 66.67 & 100 & 240 & 80.00 & 100 \\
\hline $\begin{array}{l}\text { Hum. Epicondylar } \\
\text { Br. } \\
\text { Fem. Max. Vert. }\end{array}$ & 99,12 & 57 & 68.69 & 100 & 56 & 82.41 & 92.31 \\
\hline Diam. Head & 123, 31 & 43 & 65.85 & 100 & 42 & 84.17 & 96.67 \\
\hline $\begin{array}{c}\text { Clavicle Max. Length } \\
\text { Hum. Head Max. }\end{array}$ & 27,10 & 147 & 51.85 & 100 & 143 & 70.83 & 81.82 \\
\hline $\begin{array}{c}\text { Diam. } \\
\text { Epicondylar Br. }\end{array}$ & 115,27 & 43 & 46.96 & 100 & 42 & 66.95 & 100 \\
\hline Femur & 37,9 & 78 & 64.86 & 100 & & & \\
\hline $\begin{array}{c}\text { Radius Max. Length } \\
\text { Humerus Max. }\end{array}$ & 45,11 & 232 & 53.33 & 100 & & & \\
\hline $\begin{array}{c}\text { Length } \\
\text { Tibia Max. Prox. }\end{array}$ & 54,17 & 300 & 48.15 & 100 & & & \\
\hline $\begin{array}{c}\text { Epiph. Br. } \\
\text { Fem. Trans. Diam }\end{array}$ & 88,11 & 73 & 52.27 & 100 & & & \\
\hline Midshaft & 54,25 & 25 & 50.00 & 100 & & & \\
\hline $\begin{array}{l}\text { Tibia Length } \\
\text { Circum. Tibia }\end{array}$ & 54,22 & 354 & 44.44 & 90.91 & & & \\
\hline Midshaft & 123,18 & 88 & 65.85 & 94.44 & & & \\
\hline Femur Max. Length & 59,22 & 430 & 30.51 & 95.45 & & & \\
\hline
\end{tabular}


TABLE 4—Comparison of basic statistics for males across all comparable postcranial measurements in the three comparative samples, units in millimetres.

\begin{tabular}{|c|c|c|c|c|}
\hline Measurement & Sample* & $\mathbf{N}$ & Mean & Std Dev \\
\hline \multirow[t]{3}{*}{ Humerus Head Max. Diameter } & Guatemalan & 140 & 42.83 & 2.35 \\
\hline & SSP & 63 & 45.29 & 3.02 \\
\hline & TSP & 74 & 45.92 & 2.59 \\
\hline \multirow[t]{3}{*}{ Humerus Epicondylar Br. } & Guatemalan & 120 & 58.00 & 2.72 \\
\hline & SSP & 64 & 59.70 & 4.02 \\
\hline & TSP & 73 & 61.05 & 3.88 \\
\hline \multirow[t]{3}{*}{ Ulna Maximum Length } & Guatemalan & 35 & 249.94 & 14.53 \\
\hline & SSP & 46 & 253.74 & 18.80 \\
\hline & TSP & 57 & 261.75 & 14.98 \\
\hline \multirow[t]{3}{*}{ Clavicle Max. Length } & Guatemalan & 27 & 149.33 & 9.59 \\
\hline & SSP & 52 & 151.44 & 9.36 \\
\hline & TSP & 48 & 154.63 & 7.93 \\
\hline \multirow[t]{3}{*}{ Fem. Max. Vert. Diam. Head } & Guatemalan & 143 & 43.82 & 2.23 \\
\hline & SSP & 78 & 44.64 & 2.89 \\
\hline & TSP & 81 & 45.98 & 2.57 \\
\hline \multirow[t]{2}{*}{ Humerus Max. Length } & Guatemalan & 56 & 299.16 & 15.49 \\
\hline & TSP & 77 & 317.03 & 17.69 \\
\hline \multirow[t]{2}{*}{ Radius Maximum Length } & Guatemalan & 47 & 232.19 & 13.24 \\
\hline & TSP & 58 & 244.98 & 13.53 \\
\hline \multirow[t]{2}{*}{ Epicondylar Breadth of Femur } & Guatemalan & 40 & 79.13 & 3.73 \\
\hline & TSP & 76 & 83.08 & 4.73 \\
\hline \multirow[t]{2}{*}{ Fem. Trans. Diam Midshaft } & Guatemalan & 71 & 24.88 & 1.63 \\
\hline & TSP & 95 & 30.60 & 2.80 \\
\hline \multirow[t]{2}{*}{ Femur Max. Length } & Guatemalan & 60 & 419.45 & 19.23 \\
\hline & TSP & 87 & 446.34 & 24.93 \\
\hline \multirow[t]{2}{*}{ Circumference of Tibia Midshaft } & Guatemalan & 130 & 89.75 & 5.58 \\
\hline & TSP & 70 & 94.04 & 7.72 \\
\hline \multirow[t]{2}{*}{ Tibia Max. Prox. Epiph. Br. } & Guatemalan & 102 & 73.32 & 3.37 \\
\hline & TSP & 69 & 76.93 & 4.41 \\
\hline \multirow[t]{2}{*}{ Tibia Length } & Guatemalan & 55 & 348.76 & 18.99 \\
\hline & TSP & 22 & 369.72 & 24.75 \\
\hline
\end{tabular}

